\title{
A Two-Step Procedure for Purification of Papain From Extract of Papaya Latex ${ }^{1}$
}

\author{
DAVID E. BURKE, SIDNEY D. LEWIS, AND JULES A. SHAFER ${ }^{2}$
}

\author{
Department of Biological Chemistry, The University of Michigan, Ann Arbor, Michigan 48104
}

Received February 25, 1974

\begin{abstract}
A method is presented for purifying papain from extracts of papaya latex. The procedure involves precipitation of the extract of papaya latex with sodium chloride followed by affinity chromatography of the redissolved precipitate. Precipitation of the protein from the latex extract is necessary to separate the papain from material which interferes with the binding of papain to the affinity column. During affinity chromatography, the affinity column is overloaded to insure absence in the final product of impurities which are capable of binding to the affinity column.

The papain prepared by this procedure yielded an amino acid analysis and an $\mathrm{N}$-terminal amino acid analysis expected for a sample of pure papain. No Met was detected on amino acid analysis nor was the presence of $\mathrm{N}$-terminal residues other than Ile detected. On polyacrylamide disc gel electrophoresis at $\mathrm{pH} 4.3$, papain prepared by the method described in this work was indistinguishable from crystalline papain which was prepared by the method of Kimmel and Smith, and further purified by affinity chromatography. Both disc gel patterns consisted of a single band and a trailing shadow which was less than $5 \%$ of the main hand. In routine spectrophotometric assays, the specific activity toward $N, \alpha$-benzoyl-L-arginine ethyl ester of papain prepared by the procedure described in this work was indistinguishable from crystalline papain prepared by the method of Kimmel and Smith, and further purified by affinity chromatography. Values of $24 \mathrm{sec}^{-1}$ and $15 \mathrm{~mm}$ were obtained from the turnover number and $K_{m}$ for the papain-catalyzed hydrolysis of $N, \alpha$-benzoyl-L-arginine ethyl ester at $25^{\circ} \mathrm{C}, \mathrm{pH} 6.00, \Gamma / 20.30 \mathrm{using}$ a $\mathrm{pH}$ stat.
\end{abstract}

Papain (EC 3.4.4.10) is routinely purified from papaya latex by the method of Kimmel and Smith (1). This procedure involves extraction of the latex, removal of material insoluble in the extract at $\mathrm{pH} \mathrm{9,}$ an ammonium sulfate precipitation followed by three recrystallizations. The resulting protein contains three components, active papain, activatable papain, and nonactivatable papain. The differences between these components appear associated with the state of the active-site thiol group. In active papain, the thiol group is fully reduced $(2,3)$. Activatable papain, which

${ }^{1}$ Financial support for this work from the National Institutes of Health (Research Grant AM 09276 and Postdoctoral Fellowship GM 55007) is gratefully acknowledged.

${ }^{2}$ To whom inquiries regarding this work should be addressed. itself is inactive, can be converted to active papain by reaction with thiols. Klein and Kirsch (4) presented convincing evidence which shows that, in activatable papain, the thiol group is in a disulfide linkage with the amino acid cysteine. Nonactivatable papain can not be activated to an enzymically active material by the addition of thiols.

Two elegant procedures have been developed recently to separate nonactivatable papain from active papain. One procedure employs affinity chromatography on a column consisting of the inhibitor Gly-GlyTyr(Bzl)-Arg covalently linked to Sepharose (5). The other procedure makes use of the presence of a reactive thiol group in active papain and the absence of such a thiol group in nonactivatable papain (6). In this method, active papain is separated 
from nonactivatable papain on a column of Sepharose containing covalently linked $p$ aminophenyl-mercury groups. Both methods yield active papain containing one thiol group per molecule of protein.

In theory, it should be possible to apply the affinity chromatography procedure developed by Blumberg et al. (5) directly to the papaya extract and thereby considerably reduce the time and effort necessary to obtain pure papain from the papaya extract. In practice, however, we have found that papain in the crude extract is poorly absorbed by the affinity column. In this work, a facile procedure, employing affinity chromatography, is developed for preparing papain from the extract of the papaya latex.

\section{MATERIALS AND METHODS}

Papain. Papain prepared by the method of Kimmel and Smith (1), and chymopapain (3.4.4.1) were obtained from Worthington Biochemical Corp., Freehold, NJ. The distilled water supplied to the laboratory was passed through a Barnstead demineralizer and redistilled in an all-glass still.

Extract of the papaya latex. Crude papaya latex (Type I latex from Sigma Chemical Co., St. Louis, MO) was extracted in a manner similar to that of Kimmel and Smith (1). All operations were carried out at room temperature. Papaya latex and powdered papaya latex extract were handled in a hood to avoid development of an allergic response to the latex dust. After $120 \mathrm{~g}$ of crude latex was ground in a mortar to a fine powder, $100 \mathrm{~g}$ washed and ignited sand (Fisher) and Celite-535 (67 g) were added and the mixture ground for $10 \mathrm{~min}$. A $250-\mathrm{ml}$ portion of a freshly prepared cysteine solution $(4.2 \mathrm{~g}, 24 \mathrm{mmoles}$, Lcysteine- $\mathrm{HCl} \cdot \mathrm{H}_{2} \mathrm{O}$ in $666 \mathrm{ml}$ of $0.054 \mathrm{M} \mathrm{NaOH}$ ) was then added to the mortar and the mixture ground for another $10 \mathrm{~min}$. After settling, the upper half of the mixture was filtered by suction through five sheets of filter paper (Will No. 13071) on a 15-cm Büchner funnel. The solid was returned to the mortar, and ground with another $250-\mathrm{ml}$ portion of cysteine solution for $10 \mathrm{~min}$. The mixture was filtered on the Büchner funnel, and the filter cake washed on the funnel with the remaining $166 \mathrm{ml}$ of cysteine solution and then with $50 \mathrm{ml}$ water. The combined filtrates $(670 \mathrm{ml})$ containing 5440 units of papain was adjusted to $\mathrm{pH} 9.0$ by slow addition of $1.0 \mathrm{M} \mathrm{NaOH}(85 \mathrm{ml})$, and the resulting suspension was centrifuged at $10,000 \mathrm{~g}$ for $30 \mathrm{~min}$. The supernatant solution containing 4500 units of papain in $750 \mathrm{ml}$ was removed and the solution adjusted to $\mathrm{pH} 5$ by slow addition of $0.5 \mathrm{M}$ $\mathrm{HCl}(180 \mathrm{ml})$. The activity of the solution was adjusted to 2.8 units $/ \mathrm{ml}$ by addition of water $(665 \mathrm{ml}$ were required).

Powdered extract of the papaya latex (Type II latex) was obtained from Sigma Chemical Co., St. Louis, Mo.

Papain from laboratory prepared extract of the papaya latex. Solid sodium chloride, $0.344 \mathrm{~g} / \mathrm{ml}$ was added slowly to a freshly prepared stirred solution of the extract at pH 5 (see above). After standing $2 \mathrm{hr}$ at room temperature, the precipitate was collected by centrifugation at $10,000 \mathrm{~g}$ for $40 \mathrm{~min}$. The precipitate was dissolved in $900 \mathrm{ml}$ activating buffer $(20 \mathrm{~mm}$ EDTA, $10 \mathrm{~mm}$ acetate buffer at $\mathrm{pH} 5.0$ to which 0.72 $\mathrm{ml}$ of $\beta$-mercaptoethanol per $900 \mathrm{ml}$ had been added prior to use). Insoluble material was removed by centrifugation at $10,000 \mathrm{~g}$ for $30 \mathrm{~min}$. The clear supernatant solution of papain containing 2600 units of papain in $990 \mathrm{ml}$ was subjected to affinity chromatography on a $4.3-\mathrm{cm}$ diam $\times 6 \mathrm{~cm}$ column of Sepharose $4 \mathrm{~B}$ containing covalently linked Gly-Gly-Tyr(Bzl)Arg, which was prepared and operated according to a method similar to that of Blumberg et al. (5).

After equilibrating the column by washing it with $150 \mathrm{ml}$ of eluting solution $(20 \mathrm{~mm}$ EDTA, $5.6 \mathrm{~mm}$ $\beta$-mercaptoethanol at $\mathrm{pH} 4$.21), the solution of papain was applied to the column at a flow rate of $20 \mathrm{ml}$ $\min ^{-1}$. The nonbinding fraction began to come off the column before the entire sample was applied to the column. After the entire sample was on the column, elution was continued with $20 \mathrm{~mm}$ EDTA, $5.6 \mathrm{~mm}$ $\beta$-mercaptoethanol at $\mathrm{pH} 4.21$ until most of the nonbinding material was removed from the column as judged by the absorbance $\left(A_{e}\right)$ of the eluent at $280 \mathrm{~nm}$ (approximately $700 \mathrm{ml}$ of eluent was required before $\left.A_{e} \leq 0.15\right)$. After further elution with $200 \mathrm{ml}$ of $20 \mathrm{~mm}$ EDTA, pH 4.21 to remove $\beta$-mercaptoethanol and remaining nonbinding material $\left(A_{e}<0.05\right)$; the papain was eluted from the column with water. The yield of pure papain was 976 units in $356 \mathrm{ml}$ or $715 \mathrm{mg}$ of pure papain as judged from the absorbance of the solution at $280 \mathrm{~nm}$ and a value of $\epsilon_{280}$ of 24.7 (7). The affinity column used in this work bound approximately $760 \mathrm{mg}$ of papain from the solution of the sodium chloride precipitate of the papaya latex extract. It should be noted that the affinity column has been purposely overloaded in this procedure. The papain was converted to its $\mathrm{Hg}$-derivative by addition of a $10 \%$ excess of $\mathrm{HgCl}_{2}$ to the papain and stored at $5^{\circ} \mathrm{C}$.

Papain from a commercially available powdered extract of the papaya latex. The powdered extract 100 $\mathrm{g}$ was dissolved in $1300 \mathrm{ml}$ of activating buffer $(20 \mathrm{mM}$ EDTA, $10 \mathrm{~mm}$ acetate buffer, pH 5.0 to which $\beta$-mercaptoethanol, $1.04 \mathrm{ml} / 1300 \mathrm{ml}$, was added prior to use). Insoluble material was removed by centrifugation at $10,000 \mathrm{~g}$ for $15 \mathrm{~min}$. Sodium chloride $0.337 \mathrm{~g} / \mathrm{ml}$ of supernatant was added to the supernatant which contained 2.85 units $/ \mathrm{ml}$ of papain (total of 4080 
units). After $2 \mathrm{hr}$ at room temperature, the precipitate was collected by centrifugation at $10,000 \mathrm{~g}$ for $30 \mathrm{~min}$. The precipitate was redissolved in $1000 \mathrm{ml}$ of activating buffer, and insoluble material removed by centrifugation at $10,000 \mathrm{~g}$ for $30 \mathrm{~min}$. The supernatant containing 3200 units of papain was subjected to affinity chromatography as described above. Approximately $700 \mathrm{ml}$ of eluting solution was required to elute the nonbinding material from the column. The yield of papain was $745 \mathrm{mg}$ ( 1020 units) in $450 \mathrm{ml}$ of water.

Amino acid analyses were determined by the method of Spackman et al. (8) except that after development of the color, the absorbance at $570 \mathrm{~nm}$ was measured continuously on a Gilford Model 2000 multiple sample absorbance recorder with 0.5 - and 1-cm flow-through cells. The amino acid analyzer was calibrated with an 18-amino acid standard solution from Calbiochem, Los Angeles, CA.

Disc gel electrophoreses were performed at $\mathrm{pH} 4.3$ by the method of Reisfeld et al. (9) on the $\mathrm{Hg}$ derivatives of papain.

N-Terminal analyses were performed using a method similar to one described by Fraenkel-Conrat et al. (10). The mercury derivative of the papain, 0.4 $\mathrm{ml}$ at $12-14 \mathrm{mg} / \mathrm{ml}$ was dinitrophenylated by stirring for $2.5 \mathrm{hr}$ with $5 \mathrm{mg} \mathrm{NaHCO}_{3}$ and $0.8 \mathrm{ml}$ of a $5 \% \mathrm{v} / \mathrm{v}$ solution of fluoro 2,4-dinitrobenzene in ethanol. Dnp ${ }^{3}$ amino acids were identified by thin-layer chromatography on polyamide sheets (Cheng Chin Trading Co. Ltd. Taiwan) by a method suggested by Wang and Weinstein (11) using $N$-butanol-acetic acid $(90: 10$ $\mathrm{v} / \mathrm{v}, 3.3 \mathrm{hr}$ ) in the first dimension and formic acid-water $(50: 50 \mathrm{v} / \mathrm{v}, 1 \mathrm{hr})$ in the second direction. A sample containing just the extract from the hydrolyzed dinitrophenylated papain was spotted on one side of the polyamide sheet and the same sample plus Dnp-Ile was spotted on the other side of the polyamide sheet. In all cases, only two spots were obtained, one corresponding to Dnp-Ile and one corresponding to 2,4-dinitrophenol. Standard Dnp amino acids were obtained from Calbiochem, Los Angeles, CA.

Assays of catalytic activity were performed by following the papain-catalyzed hydrolysis of BzArgOEt (Aldrich, analyzed) spectrophotometrically using a Gilford Model 240 recording spectrophotometer. Prior to assay, an aliquot of the enzyme solution was incubated with 10 parts of a solution containing $200 \mathrm{~mm} \beta$-mercaptoethanol, $50 \mathrm{~mm}$ EDTA at $\mathrm{pH} 4.21$. After $10 \mathrm{~min}, 0.1 \mathrm{ml}$ of this solution was added to a cuvette thermally equilibrated at $25^{\circ} \mathrm{C}$ and containing $3.0 \mathrm{ml}$ of $0.05 \mathrm{M}$ acetate buffer at $\mathrm{pH} 5.00$ and $0.1 \mathrm{ml}$ of freshly prepared $15.5 \mathrm{~mm} \mathrm{BzArgOEt}$ in water. After mixing, the linear time dependence of absorbance at $255 \mathrm{~nm}$ was recorded using a recorder sensitivity of 0.01 absorbance unit/in. The slopes of

${ }^{3}$ Abbreviations used are: BzArgOEt, $N, \alpha$-benzoylL-arginine ethyl ester; $\mathrm{BzArg}, N, \alpha$-benzoyl-L-arginine; Dnp, dinitrophenyl. absorbance vs time plots were related to the velocity of decomposition of substrate using the difference in molar absorbtivities between BzArgOEt and BzArg and the total volume of the assay solution. One unit is defined as that amount of sample which causes the decomposition of $1 \mu$ mole of substrate per $\min$ in the spectrophotometric assay. For determination of the turnover number and $K_{m}$, initial velocities for the decomposition of substrate were determined using a Radiometer TTT-1C pH Stat. The titrant was $0.05 \mathrm{~N}$ $\mathrm{KOH}, 0.25 \mathrm{~N} \mathrm{KCl}$. The sample was maintained at 25 $\pm 0.2^{\circ} \mathrm{C}$ with water from a constant-temperature circulator.

\section{RESULTS AND DISCUSSION}

Table I summarizes the isolation of pure papain from commercially available dried papaya latex. Roughly, $6 \mathrm{mg}$ of pure papain per $\mathrm{g}$ of latex was routinely obtained. A similar yield of papain (Table I) can be obtained starting with a commercially available powdered latex extract (Sigma, Type II latex) which is soluble in the extracting buffer. Kimmel and Smith (1) obtained 6-7 mg of papain per $\mathrm{g}$ of latex. However, the papain obtained by this more time-consuming method contained about $50 \%$ nonactivatable papain (5). Further purification of this sample of papain by affinity chromatography, results in a net yield of only 3-4 mg pure papain/g latex. Application of a solution of the latex extract in activating buffer directly to the affinity column results in a 8-fold decrease in the capacity of the affinity column. Material which prevents binding to the affinity column must be present in the latex extract. This material is separated from the papain by precipitating the papain with sodium chloride. The affinity column used in this work had a similar capacity for absorbing papain from both of the dissolved sodium chloride precipitates described in this work and a solution of crystalline papain prepared by the method of Kimmel and Smith (1). Inhibitors of papain have been reported present in the extract of the papaya latex $(1,12)$. Perhaps, it is these inhibitors that compete with the affinity column for papain and thereby reduce the working capacity of the column.

Repeated use of the affinity column for preparing papain resulted in only a small 
TABLE I

Purification of Papain from Papaya Latex

\begin{tabular}{|c|c|c|c|c|}
\hline \multirow{2}{*}{$\frac{\text { Starting material }}{\text { Solution }}$} & \multicolumn{2}{|c|}{120 g Type I latex } & \multicolumn{2}{|c|}{$100 \mathrm{~g}$ Type II latex } \\
\hline & $\underset{(\mathrm{ml})}{\text { Volume }}$ & Total units & $\underset{(\mathrm{ml})}{\text { Volume }}$ & Total units \\
\hline Initial latex extract & 670 & 5440 & & \\
\hline pH 9 solution & 750 & 4500 & & \\
\hline pH 5 solution & 940 & 4560 & 1340 & 4080 \\
\hline $\mathrm{NaCl}$ supernatant & 1670 & 1750 & 1380 & 1530 \\
\hline Redissolved $\mathrm{NaCl}$ ppt & 990 & 2600 & 1130 & 3200 \\
\hline $\begin{array}{l}\text { Affinity chromatography of } \\
\text { redissolved } \mathrm{NaCl} \text { ppt }\end{array}$ & & & & \\
\hline Nonbinding fraction & 1920 & 1300 & 1860 & 2040 \\
\hline Papain fraction & 356 & $\begin{array}{c}976 \\
(715 \mathrm{mg})^{a}\end{array}$ & 450 & $\begin{array}{c}1020 \\
(745 \mathrm{mg})^{a}\end{array}$ \\
\hline Trailings and column wash & 490 & 60 & 500 & 44 \\
\hline
\end{tabular}

a The yield of papain was determined from the absorbance of the solution at $280 \mathrm{~nm}$ using a value of 24.7 for $\epsilon_{280}^{1 \%}$.

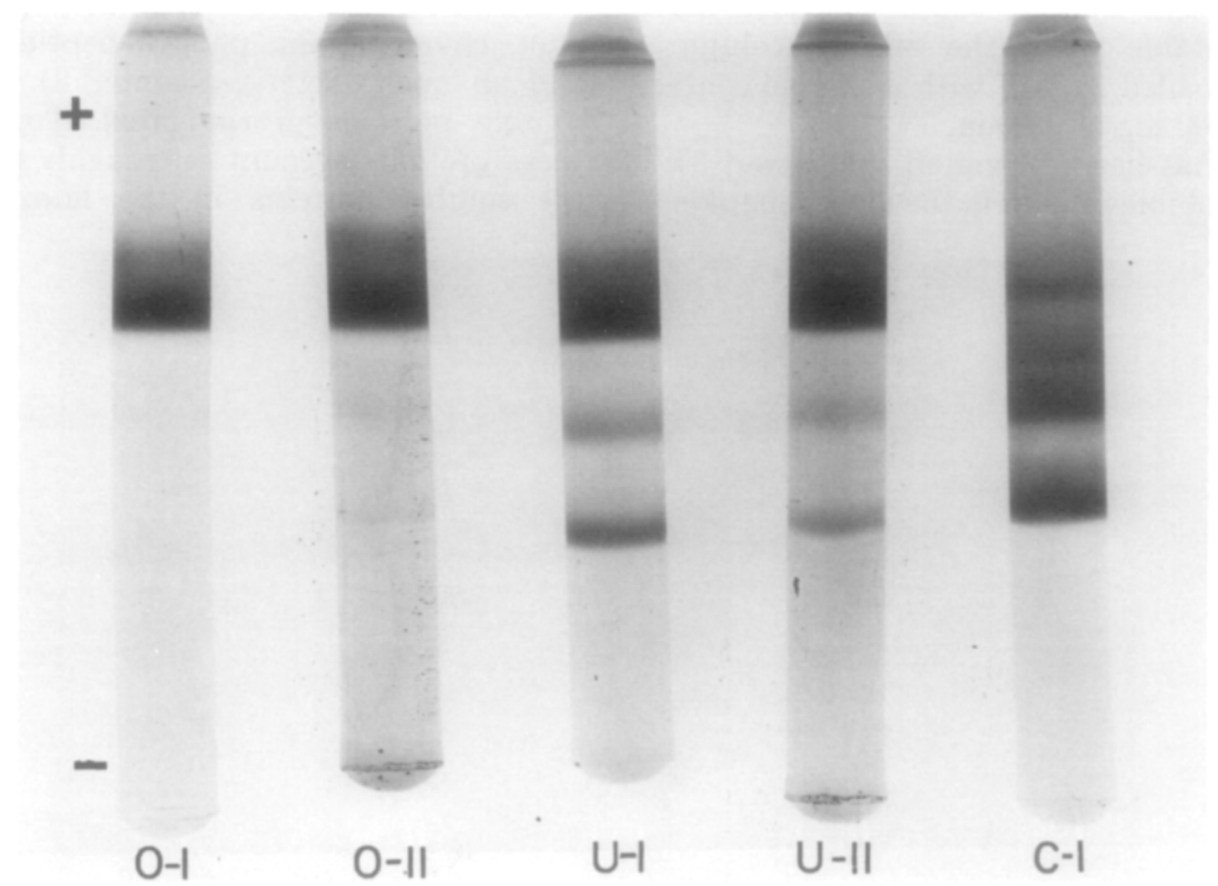

Fig. 1. Effect of overloading the affinity column on electrophoretic patterns at $\mathrm{pH} 4.3$ on polyacrylamide disc gels. Papain $(50 \mu \mathrm{g})$ from type I preparation in Table I (O-I) and papain from type II latex (O-II) with the affinity column $20 \%$ overloaded. Papain $(50 \mu \mathrm{g})$ from type I (U-I) and type II (U-II) latex with the affinity column loaded below capacity. (C-I) Crude type I latex extract $(50 \mu \mathrm{g})$.

change in the column's working capacity. loading of the affinity column. When a After processing more than $1 \mathrm{~kg}$ of latex, smaller amount of redissolved sodium chlothe affinity column lost less than $15 \%$ of its ride precipitate is applied to the affinity working capacity.

An important aspect of the purification procedure depicted in Table $I$ is the overcolumn, so that the column is not overloaded, $9.6 \mathrm{mg}$ and $12.6 \mathrm{mg}$ of papain were routinely obtained per $g$ of Type I latex and 
Type II latex, respectively. However, this increased yield of papain is accompanied by $5 \%$ impurity which shows up as two leading bands on electrophoresis of the papain. The fact that these bands disappear on overloading the column (Fig. 1) indicates that these impurities bind to the column less tightly than papain. When the affinity column is overloaded, impurity has to compete with the papain for the sites on the column and the binding of the impurity to the column is markedly reduced. The affinity column in the purification procedures depicted in Table $\mathrm{I}$ is overloaded somewhat more than necessary. The minimum overloading necessary for eliminating impurities (the two leading bands on disc gel electrophoresis) is about $20 \%$. Examination of photograph O-II in Fig. 1 reveals that the leading bands are just barely detectable when the affinity column is overloaded by $20 \%$ with a sample containing $900 \mathrm{mg}$ of papain.

It has been estimated that about $5 \%$ of the soluble protein in the latex is papain (1,
13). However, only about half of this $5 \%$ is active papain. When the affinity column is not overloaded, we recover $2-3 \%$ of the soluble latex protein as active papain in a fraction which is $90 \%$ pure active papain. This yield, which is probably close to complete recovery of the active papain in the latex extract is reduced by about $20-40 \%$ when the affinity column is overloaded. Of the 45 units in the extract of $1 \mathrm{~g}$ of crude papaya latex (Type I latex), 9.6 mg or 13 units of papain can be recovered when the affinity column is not overloaded. Thus, at least $29 \%$ of the catalytic activity of the latex toward BzArgOEt is present as papain. The remainder of the activity probably arises from other proteolytic enzymes in the papaya extract. Schack (13) demonstrated the existence of four main components with proteolytic activity (papain, chymopapain, papaya peptidase-A, and an uncharacterized material) in the soluble proteins of the latex. Together, these proteins account for roughly $64 \%$ of the soluble proteins in the latex. The

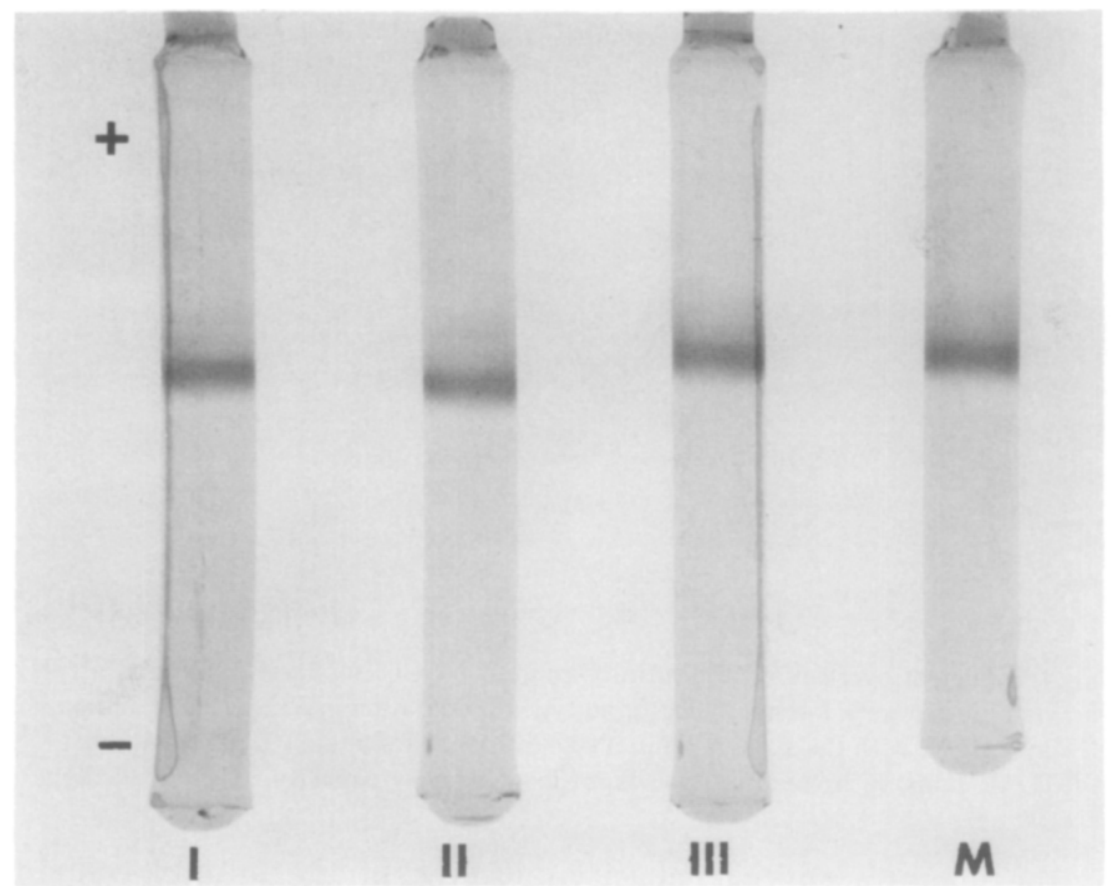

FIG. 2. Identity of three samples of papain with respect to polyacrylamide disc gel electrophoresis at $\mathrm{pH}$ 4.3. Papain $(6 \mu \mathrm{g})$ purified from type I latex (I) and type II latex (II). Papain obtained by the method of Kimmel and Smith (1) and further purified by affinity chromatography using the method of Blumberg et al. (5) (III). Mixture of $2 \mu \mathrm{g}$ of each of the material from I, II, and III (M). 
fraction designated chymopapain is the most abundant proteolytic component in the extract (13). Affinity chromatography of chymopapain showed that less than $1 \%$ of the chymopapain was bound to the affinity column under the conditions used to purify papain. Chymopapain appears to consist of several components (14), which contain one or more residues of Met, and either Glu or Tyr at the amino terminus (14). The absence of Met in the samples of purified papain (Table II), and the absence of any amino terminal Glu or Tyr in the samples of papain, rules out significant contamination of papain by chymopapain. The amino acid analysis also eliminates the possibility of significant contamination by papaya peptidase-A, since this material has a Lys and His content twice that of papain and an Asp and Phe content half that of papain (13).

Papain prepared by the method of Kimmel and Smith (1) and further purified by the affinity chromatography procedure of Blumberg et al. (5) was compared to the two samples of papain prepared by the methods summarized in Table I. All three samples behaved identically on acrylamide gel electrophoresis (Fig. 2). In addition to the main band, it was possible to detect a shadow trailing the main band. By diluting samples until the intensity of the main band was equal in intensity to the trailing shadow in the undiluted sample, it was estimated that this shadow corresponded to less than $5 \%$ that of the papain. The amino acid analysis of the three samples of papain were within experimental error of that expected for papain (Table II). The three samples of papain showed only two yellow components after hydrolysis of the dinitrophenylated proteins followed by two-dimensional thin-layer chromatography on polyamide sheets according to the method of Wang and Weinstein (11). The two yellow components corresponded to Dnp-Leu or Dnp-Ile and 2,4-dinitrophenol. In our hands, this method did not clearly resolve Dnp-Leu from Dnp-Ile. However, we were able to resolve all the other Dnp-amino acids from Dnp-Leu and Dnp-Ile.
TABLE II

Amino Acid Analysis of Three Samples of Papain After Affinity Chromatography

\begin{tabular}{|c|c|c|c|c|}
\hline & \multicolumn{3}{|c|}{ Residues $a /$ molecule } & \multirow{2}{*}{$\begin{array}{l}\text { Lit. } \\
\text { value }^{\circ}\end{array}$} \\
\hline & $\begin{array}{l}\text { Type I } \\
\text { latex }\end{array}$ & $\begin{array}{c}\text { Type II } \\
\text { latex }\end{array}$ & $\begin{array}{l}\text { Crystalline } \\
\text { papain pre- } \\
\text { pared by } \\
\text { the method } \\
\text { of Kimmel } \\
\text { and Smith }\end{array}$ & \\
\hline Lys & 10.6 & 10.4 & 10.2 & 10 \\
\hline His & 1.9 & 1.8 & 1.8 & 2 \\
\hline Arg & 11.6 & 11.4 & 11.6 & 12 \\
\hline $\begin{array}{r}\text { Asp }+ \\
\text { Asn }\end{array}$ & 18.6 & 19.9 & 19.1 & 19 \\
\hline Thr & 7.5 & 7.6 & 6.7 & 8 \\
\hline Ser & 12.9 & 11.6 & 12.2 & 13 \\
\hline $\begin{array}{r}\text { Glu + } \\
\text { Gln }\end{array}$ & 22.5 & 22.3 & 21.9 & 20 \\
\hline Gly & 30.0 & 29.2 & 28.7 & 28 \\
\hline Ala & 15.3 & 13.5 & 16.0 & 14 \\
\hline Met & $0^{c}$ & $0^{c}$ & $0^{c}$ & 0 \\
\hline Ile & 10.0 & 11.3 & 11.1 & 12 \\
\hline Leu & 10.2 & 11.6 & 10.9 & 11 \\
\hline Tyr & 17.3 & 17.4 & 17.8 & 19 \\
\hline Phe & 3.6 & 3.8 & 4.1 & 4 \\
\hline
\end{tabular}

a The nmoles of the listed residues which were recovered on amino acid analysis were summed and divided by 172 , the lit value for the sum of the listed residues to yield the nmoles of papain analyzed. Proline, 1/2 cysteine, and valine were not analyzed.

${ }^{b}$ Taken frum Ref. (14).

c No Met was detected where 0.2 residue of Met would have been detected.

With BzArgOEt as substrate (at pH 6.0, $\left.25^{\circ} \mathrm{C}, \mathrm{T} / 20.30\right)$, papain purified from Type I latex material yielded values of $14.5 \mathrm{~mm}$ and $23.6 \mathrm{sec}^{-1}$ for $K_{m}$ and the turnover number. These values are in tolerable agreement with the values of $18 \mathrm{~mm}$ and $28.5 \mathrm{sec}^{-1}$ for $K_{m}$ and the turnover number obtained under similar conditions by Blumberg et al. (5) for papain prepared by the method of Kimmel and Smith (1), and further purified by affinity chromatography. The routinely used spectrophotometric assays for catalytic activity yielded specific activities with experimental error of each other for the three samples of papain purified in this work.

Thus, in addition to decreasing greatly the time and effort necessary for obtaining papain from the latex extract, the proce- 
dure described here yields papain which is equivalent in purity to crystalline papain prepared by the method of Kimmel and Smith (1) and then further purified by affinity chromatography, by the method of Blumberg et al. (5).

\section{REFERENCES}

1. Kimmel, J. R., AND SMith, E. L. (1954) J. Biol. Chem. 207, 515-531.

2. Kimmel, J. R., AND Smith, E. L. (1957) Advan. Enzymol. 19, 267-334.

3. Sanner, T., and Pihl, A. (1963) J. Biol. Chem. $238,165-171$.

4. Klein, I. B., AND Kirsch, J. F. (1969) J. Biol. Chem. 244, 5928-5935.

5. Blumberg, S., Schechter, I., AND Berger, A. (1970) Eur. J. Biochm. 15, 97-102.

6. Sluyterman, L. A. Ae, and Widdenes, J. (1970) Biochim. Biophys, Acta 200, 593-595.

7. Begúe-Cantón, M. L., Blakeley, R. L., BruBacher, L. J., Feder, J., Gunter, C. R.,
KÉzDy, F. J., KillhefFER, JR., J. V., MaRshall, T. H., Miller, C. G., Roeske, R. W., and Stoops, J. K. (1966) J. Amer. Chem. Soc. 88, 5890-5913.

8. Spackman, D. H., Stein, W. H., and Moore, S. (1958) Anal. Chem. 30, 1190.

9. Reisfeid, R. A., Lewis, U. J., and Williams, D. E. (1962) Nature (London) 195, 281-283.

10. Fraenkel-Conrat, H., Harris, J. I., and Levy, A. L. (1955) Methods Biochem Anal 2, 359-425.

11. Wang, K.-'T', and Weinstein, B. (1971) in Progress in Thin-Layer Chromatography and $\mathrm{Re}$ lated Methods (Niederwieser, A., and Pataki, G., eds.), Vol. III, p. 177-231. Ann Arbor-Humphrey Science Publ., Ann Arbor, MI.

12. Perlstein, S. H., and Kezdy, F. J. (1973) J. Supramolec. Struct., 249-253.

13. Schack, P. (1967) C. R. Trav. Lab. Carlsberg 36, 67-83.

14. Kunimitsu, D. K., and Yasunobu, K. T. (1967) Biochim. Biophys. Acta 139, 405-417.

15. Mitchel, R. E. J., Chaiken, I. M., AND Smith, E. L. (1970) J. Biol. Chem. 245, 3485-3492. 